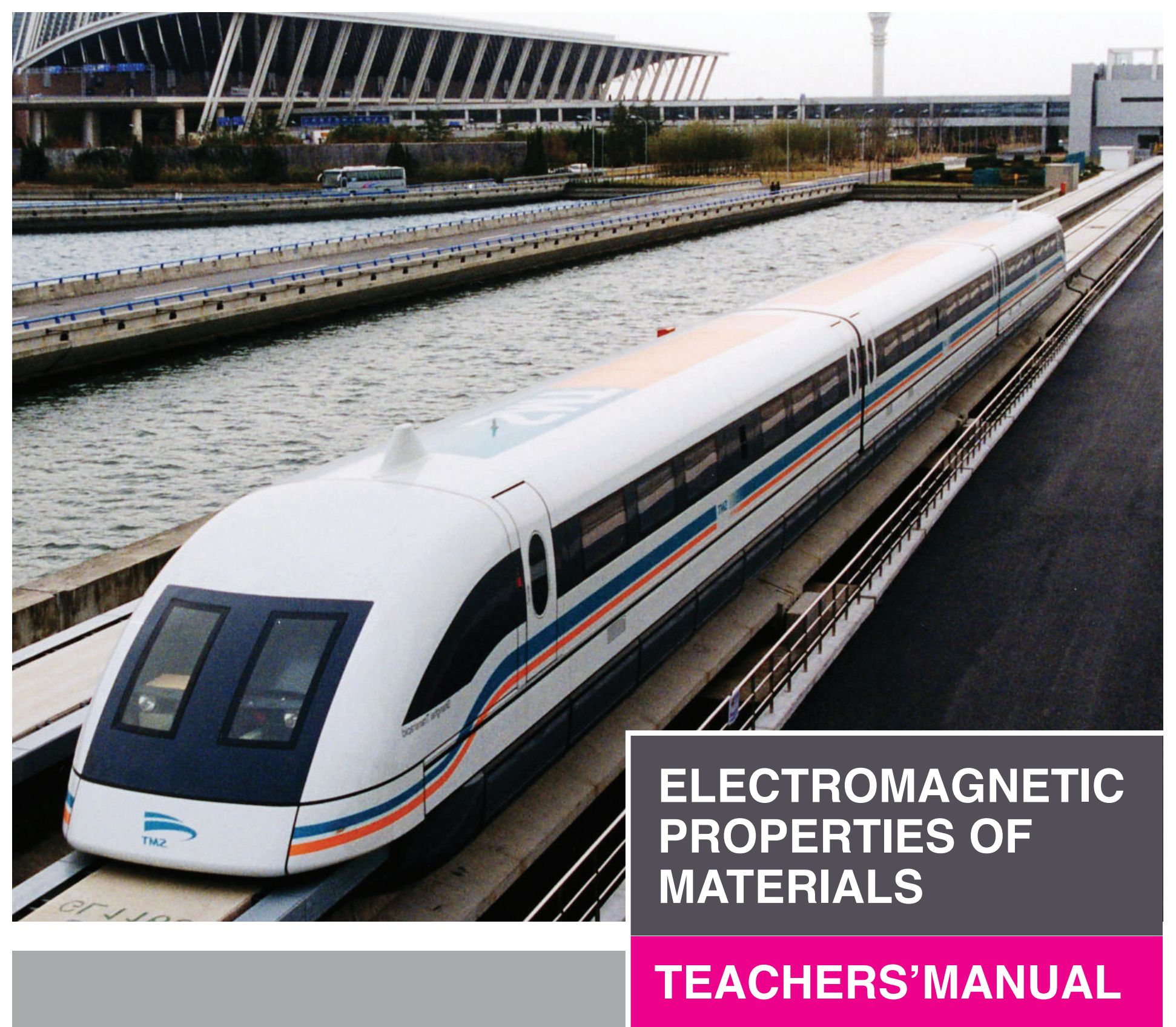

ADAPTED VERSION 



\section{MATERIALS SCIENCE PROJECT}

\author{
UNIVERSITY-SCHOOL \\ PARTNERSHIPS FOR THE DESIGN \\ AND IMPLEMENTATION OF \\ RESEARCH-BASED ICT-ENHANCED \\ MODULES ON MATERIAL \\ PROPERTIES
}

\section{SPECIFIC SUPPORT ACTIONS}

FP6: SCIENCE AND SOCIETY: SCIENCE AND EDUCATION
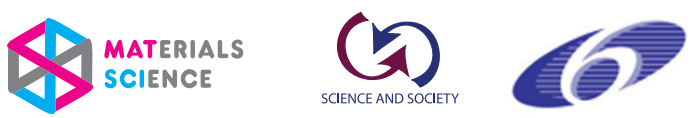

PROJECT COORDINATOR

CONSTANTINOS P. CONSTANTINOU, LEARNING IN SCIENCE GROUP, UNIVERSITY OF CYPRUS

\section{PROJECT PARTNERS}

\$ Паvemorńni Kúnо Kou University of Cyprus

ARISTOTLE UNIVERSITY Of THESSALONIKI

\section{UNIVERSITY OF}

WESTERN MACEDONIA

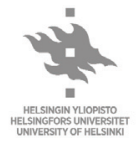

\section{UAB}

Universitat Autònoma

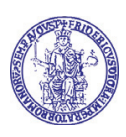

\section{ACKNOWLEDGMENT}

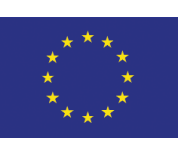

RESEARCH FUNDING FOR THE MATERIALS SCIENCE PROJECT WAS PROVIDED BY THE EUROPEAN COMMUNITY UNDER THE SIXTH FRAMEWORK SCIENCE AND SOCIETY PROGRAMME (CONTRACT SAS6-CT-2006042942).

THIS PUBLICATION REFLECTS ONLY THE VIEWS OF THE AUTHORS AND THE EUROPEAN COMMUNITY IS NOT LIABLE FOR ANY USE THAT MAY BE MADE OF THE INFORMATION CONTAINED HEREIN. 


\section{ELECTROMAGNETIC PROPERTIES OF MATERIALS}

Redesign and adaptation

University Staff

Roser Pintó

Digna Couso

María Isabel Hernández

School Teachers

Montserrat Armengol

Celsa Cortijo

Raül Martos

Miquel Padilla

Consol Rios

Marta Simón

Carme Sunyer

Montserrat Tortosa
Original design and development

Univesity Staff

Constantinos P. Constantinou

Michalis Livitziis

Rodothea Hadjilouca

Argyro Scholinaki

Marios Papaevripidou

Nikos Papadouris

Giannis Hadjidemetriou

School Teachers

Efi Loizidou

Myrto Pouangare

Other contributions

Peer review and feedback

Michalis Livitziis 



\section{CONTENTS}

\section{A: DESCRIPTION AND ANALYSIS OF TEACHING AND LEARNING ACTIVITIES}

Unit 1: Magnetic Interactions

1.1. Magnetic interactions

1.2. The parts of a magnet

08

1.3. The Earth as a magnet

09

Unit 2: Magnetic Fields

2.1. Magnetic fields

Unit 3: Model of Magnetic materials

3.1. Comparing the strength of magnets

3.2. Breaking and stacking magnets

3.3. A model for magnetic materials

Unit 4: Electromagnets

4.1. Magnetic field of a current-carrying wire

4.2. Making magnets with a current-carrying wire

4.3. Investigation with electromagnets 



\section{A: DESCRIPTION AND ANALYSIS OF TEACHING AND LEARNING ACTIVITIES}




\section{UNIT 1: MAGNETIC INTERACTIONS}

\subsection{MAGNETIC INTERACTIONS}

In this section, students explore the interaction between magnets and other materials. They classify objects into categories according to their magnetic interactions. On the basis of their observations, they develop an operational definition for the term magnet or permanent magnet. The term ferromagnetism is also introduced.

There are subtleties to magnetism that can cause confusion for some students. In this introductory section, an attempt has been made to simplify the ideas. Complexities are examined later as students develop the requisite tools for solving the issues. Students are encouraged to gain familiarity with magnetic phenomena.

\section{Equipment}

1.1.1. Two bar magnets without the poles marked and a set of various objects including: several magnets of different size and shape, some ferromagnetic objects (e.g. iron, nickel, paper clips), and objects made of non-magnetic materials (e.g., non-magnetic metals, ceramics, glass, wood). The behaviour of aluminium nails is often surprising to students.

\section{Discussion of the experiments and exercises}

1.1.1. Students may say that there are only two categories of objects: those that interact with the bar magnets (e.g., other magnets and iron nails) and those that do not. They will not recognize that their observations for the nail and the permanent magnet are different: the nail is always attracted to the magnet. (Few students, on their own will conduct the types of experiments necessary to show repulsion with the nail.) Help them to recognize that their observations suggest at least three categories of objects. Students will refine the classification scheme later in the module, after their model for magnets is sufficiently well developed to account for their observations. Some students come up with four, not three, classes of objects. They subdivide the class of objects that are attracted to magnets but not repelled. Students may notice that after contact with a magnet, some objects attract paper clips while other objects do not.

Many students will say that they observe that, for two magnets, "like" ends repel and "unlike" ends attract. Help them to recognize that this statement relies on outside knowledge and does not follow from the experiments they have performed. Encourage them to state their observations in simple, everyday terms without inferences as to why the magnets behave as they do.

1.1.2. Students may not be familiar with operational definitions. The operational definition should be a series of steps one would take to identify magnets distinguishing them from other objects. The operational definition given by students should not simply be a statement such as: "A magnet will pick up or attract paper clips". If a student gives such a response, reach over, pick up a paper clip and ask whether you are a magnet. One possible acceptable operational definition would include a statement of how to test many objects to find a set of three classes of objects that interact differently from one another according to their magnetic interactions.

1.1.3 and 1.1.4. Often students will believe that magnets attract ferromagnetic materials, but that the reverse is not true. Students who believe the interaction is one-sided should close their eyes during this experiment.

1.1.5. Students should summarize the concepts, ideas and procedures that they have learnt during this chapter using the method they are more familiar with (concept maps, writing a text, schema, etc). Students are encouraged to organize their knowledge and relate new ideas to already existing knowledge.

\subsection{THE PARTS OF A MAGNET}

The students continue their exploration of magnets by investigating how the various portions of a magnet interact magnetically. Based on their observations, the students develop an operational definition for a magnetic pole and examine the prevalence and nature of the poles in a single magnet.

Equipment 
1.2.1. Three bar magnets without the poles labelled, several sets of small adhesive coloured dots (a set of three or more colours), box with 5 "test spots" marked on it. Included among the test spots should be at least one of each of the following: a north magnetic pole, a south magnetic pole, a non-magnetic material, and a ferro $\neg$ magnetic material.

1.2.2. Magnets with ends marked from previous experiment.

1.2.3. Magnets of various shapes (e.g., horseshoe, thin round disks and hoops)

\section{Discussion of the experiments and exercises}

1.2.1. In this exercise, students develop a procedure by which to determine the "like" and "unlike" ends of several magnets. Few will have previously recognized that the process of scientific inquiry often does not yield definite answers - even to such apparently simple questions as "How many types of magnetic poles are there?".

Students develop the rule for the interaction of "like" and "unlike" magnet ends. They also determine to which of the three categories from Experiment 1.1.1 each of the test spots on their box belongs.

1.2.2. In this experiment, students examine in detail the interaction of various portions of a bar magnet with ferromagnetic materials and with other magnets. This experiment sets the stage for introducing the idea of magnetic poles.

1.2.3. In this exercise, students infer a general rule for the number and types of poles in a single magnet. Some students may find magnets that appear to have 3 poles (e.g., two north poles at the ends and 1 south pole in the centre). In this case, ask the students to consider what would happen if they were to glue two magnets together with the like poles in contact. Would they say that the magnet has only 3 poles or that it has 4 poles, two of which are spaced very closely together?

1.2.4. Students should summarize the concepts, ideas and procedures that they have learnt during this chapter using the method they are more familiar with (concept maps, writing a text, schema, etc). Students are encouraged to organize their knowledge and relate new ideas to already existing knowledge.

\subsection{THE EARTH AS A MAGNET}

Students make observations of the orientation of magnets suspended from strings. Their results are used as a basis to introduce a model in which the Earth acts like a large magnet. The terms north and south are introduced for the poles of a magnet. The students are led to recognize that the north geographic pole of the Earth is a south magnetic pole by this convention. Compasses are also introduced.

\section{Equipment}

1.3.1. String, ring stand, clamp, several unlabeled long cylindrical or bar magnets.

1.3.2. Small adhesive dots.

1.3.3. Computer simulation (http://phet.colorado.edu/simulations/sims.ph p?sim=Magnet_and_Compass).

\section{Discussion of the experiments and exercises}

1.3.1. In this experiment, students explore the behaviour of magnets suspended so they are free to rotate. They make an analogy between this situation and that of a small magnet suspended above a large magnet to develop a model for the magnetic properties of the Earth.

1.3.2. Students are introduced to the standard convention for labelling the poles of a magnet and decide on the basis of their experience whether the north geographic pole of the earth is a north or a south magnetic pole. Many students are surprised by their conclusions. The phrase that "the North Pole is a south magnetic pole" will be a continuing problem for many students. Be sure that all the students have gone through the reasoning leading to that conclusion for themselves and are not relying on a partner for the answer.

1.3.3. The compass is introduced and students explore its use. They make observations that lead them to recognize that a compass needle is a weak magnet.

1.3.4. Students should summarize the concepts, ideas and procedures that they have learnt 
during this chapter using the method they are more familiar with (concept maps, writing a text, schema, etc). Students are encouraged to organize their knowledge and relate new ideas to already existing knowledge.

\section{UNIT 2: MAGNETIC FIELDS}

\subsection{MAGNETIC FIELDS}

Students explore the region around a magnet with a compass and with iron filings. They repeat the procedure for two magnets placed near one another and recognize how the effects of the two magnets add. These exercises provide the foundation for the introduction of the concept of magnetic field.

\section{Equipment}

2.1.1. A bar magnet, a plastic bag, large sheets of paper, and iron filings.

2.1.2. A small compass, a bar magnet and large sheets of paper.

2.1.3. Two bar magnets and a small compass or iron filings.

2.1.4. Several magnets that are not bar magnets and iron filings.

\section{Discussion of the experiments and exercises}

2.1.1. Students make an iron filing pattern for a single magnet. Students could be monitored if they use the aerosol glue to make a permanent record of the pattern. They should recognize that the regions in which the interaction between the magnet and the filings is strongest is near the poles of the magnet.

2.1.2. Students are drawing magnetic lines using the compass. Students develop some of the standard rules for drawing magnetic field lines. In part A, some students may have difficulty in generalizing that all the field lines for a single magnet return to the magnet. In particular students may still be including the earth's field. In this case ask them to consider Experiment 2.1.1 again. Or students may choose a line that leaves the magnet following a straight path. Ask them what they would have gotten if they had used a smaller piece of paper or a larger piece of paper. Students who have difficulty in answering part $\mathrm{C}$ should be reminded of the method that they used to draw the field lines. Also students should be able to understand that there is nothing special on the lines and that the effect is taking place all over the space around the magnet.

2.1.3. Students begin to develop the idea of superposition in this experiment. First the students observe how a compass needle 
behaves near two magnets of equal strengths and equal distances from the compass. This is accomplished by looking at the effect of each magnet individually on the compass needle and then together. Then one of the magnets is moved further from the compass and the new total direction is noted.

2.1.4. Students explore the magnetic fields of various shape magnets.

\section{UNIT 3: MODEL OF MAGNETIC MATERIALS}

3.1. COMPARING THE STRENGTH OF MAGNETS

This chapter encourages students to analyze properties of magnets, strength of magnets in particular. Students develop a method for comparing the strengths of magnets and examine some of the factors that affect the strength of a magnet.

\section{Equipment}

3.1.2. Several unlabeled magnets of various sizes, shapes and strengths. Several compasses, paper clips and a ruler. A sensor of magnetic field could also be introduced in this experiment.

Discussion of the experiments and exercises:

3.1.1. Students develop a method for measuring the strength exerted by a magnet on an object. Various methods are possible. Some students will select to check how many paper clips can a magnet hold, other students will find the distance from which the magnet will attract a paper clip at rest on a table and other prepare chains of paper clips and check which magnet is going to hold the longest chain. Some students will become frustrated when their measurements are slightly different each time they perform the experiment. For this reason, some students would also want to check the strength exerted by each magnet by means of a sensor of magnetic field, which measures the intensity of magnetic field in a certain point of the space.

3.1.2. Students compare the strengths of several magnets and examine various factors that might affect magnetic strength.

\subsection{BREAKING AND STACKING MAGNETS}

Students observe that several magnets put together have the same characteristics of a single magnet. The observations made in this section suggest possible ways of making stronger and weaker large magnets out of small magnets. The results of this section lay the groundwork for a model for magnetism.

\section{Equipment}

3.2.1. Set of small rectangular magnets that can be assembled into a magnetic "stack," paper clips and compasses. 
3.2.2. Rubber magnet, other magnets from preceding experiment and compasses.

3.2.3. Magnets from preceding experiments, paper clips, ruler, sensor of magnetic field.

3.2.4. Two bar magnets.

\section{Discussion of the experiments and exercises:}

3.2.1. Students examine a stack of small identical magnets and compare the magnetic behaviour of the stack with that of a bar magnet.

3.2.2. Students "break" a magnet and examine qualitatively the properties of the parts.

3.2.3. Students measure the strength exerted by a magnetic stack as more magnets are added to the stack. Some students will hold very strongly to their intuitive idea that placing magnets end-to-end will result in a much stronger magnet.

3.2.4. Students analyze which arrangements of two magnets make stronger the interaction between the stack of these magnets and a ferromagnetic object.

\subsection{A MODEL FOR MAGNETIC MATERIALS}

In this section, students tie together their observations and conclusions from the entire module in order to build a model for magnetic materials. Additional activities and questions are included to help them account for the various phenomena. The term ferromagnetic is refined further.

\section{Equipment}

3.3.1. Several small magnets that can be formed into a stack.

3.3.2. Several small rectangular magnets that can be formed into a stack and several small compasses.

3.3.3. A bar magnet and several small compasses.

3.3.5. A bar magnet, a similarly sized ferromagnetic bar that is not magnetized, iron filings or compasses.

3.3.8. Two small plastic pieces, tape, a strong diskshape magnet, paper clips and some small sheets of several materials including iron, plastic, copper, aluminium, stainless-steel, etc.

Discussion of the experiments and exercises:

3.3.1. Students should begin to consider that all magnets are made up of smaller magnets and that the alignment of the smaller pieces is what determines the strength of the magnets.

3.3.2. Using the magnetic stack from Chapter 6 students check the behaviour of the compass "inside" the stack. Although their experiment yields an answer, students should recognize that they have not yet come up with a definitive answer to the question of the field inside a magnet. This result is treated again in Electromagnets.

3.3.3. This experiment should reinforce the idea that ferromagnetic objects are also made up of smaller magnets and that they are free to rotate when exposed to different fields.

3.3.4. Students should discuss the model for magnetic materials in the context of several of the observations they have made throughout the module.

3.3.5. This experiment reinforces that idea that ferromagnetic materials are just a collection of small magnets that rotate as compasses in the presence of another magnetic field. The pattern obtained for part A should be the same as if the ferromagnetic material were a bar magnet with its south pole on the right and its north pole on the left. The pattern obtained for part B should be the same as if the ferromagnetic material were a stack of small magnets with their south poles on the left and the north poles on the right.

3.3.6. and 3.3.7. Students are asked to account for some magnetic phenomena applying the model for magnetic materials.

3.3.8. Students analyze the effect of different materials on the magnetic field created by a magnet. Ferromagnetic materials affect the form of the magnetic field, they alter the direction of the magnetic lines in order for the magnetic field to pass through the ferromagnetic material.

3.3.9. Students should summarize the concepts and models that they have learnt during this chapter using the method they are more familiar with (concept maps, writing a text, schema, etc). Students are encouraged to organize their knowledge and relate new ideas to already existing knowledge. 


\section{UNIT 4: ELECTROMAGNETS}

Students realize that an electric current creates a magnetic field and that the magnetic lines form circles around a current-carrying wire. In addition, students become aware that when a wire is shaped into a coil the magnetic field looks just like the one of a bar magnet. The students confirm this by making a nail into a very strong magnet when it is placed inside the coil and there is current in the coil.

\subsection{MAGNETIC FIELD OF A CURRENT- CARRYING WIRE}

\section{Equipment}

4.1.1. Fresh battery, connecting wire, and a compass.

4.1.2. Ring stand, clamp, piece of cardboard, several compasses, fresh battery and connecting wire.

\section{Discussion of the experiments and exercises:}

4.1.1. Students perform the experiment carried out by Oersted in order to become aware that there is a certain relationship between electricity and magnetism.

4.1.2. Students explore the magnetic field of a current-carrying wire by looking at the pattern obtained by several compasses near the wire. In this and the rest of the experiments involving the magnetic field of current-carrying wires students may have difficulty determining the field for several reasons. One could ask students what the effect of the earth's field has on the pattern they are seeing.

\subsection{MAKING MAGNETS WITH A CURRENT- CARRYING WIRE}

\section{Equipment}

4.2.1. Ring stand, clamp, piece of cardboard, a fresh battery, connecting wire, and several compasses.

4.2.2. A fresh battery, connecting wire, an iron nail, and paper clips.

4.2.3. Connecting wire, a fresh battery, a small diskshape magnet, a piece of wood or polystyrene.

\section{Discussion of the experiments and exercises:}

4.2.1. Students explore the field of a coiled wire using a set up similar to that of Experiment
4.1.2. Students are asked to look at the field of a long coil of wire when there is a current through it. Students should recognize that the field of the coil is very similar to that of a bar magnet. The students are led to consider the coil as a bar magnet and are asked to identify the north and south end of it.

4.2.2. Students build an electromagnet out of an iron nail. They should observe that the nail is a very strong magnet when there is current flowing and that the poles of the magnet are where they were for the current loops from Experiment 4.2.1. In addition, the students may find that the nail remains somewhat magnetized even after the current is turned off. Students should be asked to account for this observation by considering how magnets were made in Chapter 3.3 and relate that to the field they observed for the current loops around the nail. The more sophisticated students may use their model for magnetic materials developed in Chapter 3.3 to explain their observations. These students may recognize that when there is current flow, the little magnets that make up the iron rod will align with the magnetic field to make itself a very strong magnet. In order to get such a strong magnet, the students may recognize that this orientation of the smaller magnets is not stable. So when the current is turned off, some of the smaller magnets that make up the iron rod will flip to a more stable configuration. This leaves the iron nail much weaker than before, but still behaving like a magnet overall. Experiment 4.3.2.D is aimed to help students realize that the polarity of the electromagnet depends on the direction that the current spins around its core.

4.2.3. Using the model that a coil of wire has a field similar to that of a bar magnet with a north and a south pole, students observe the behaviour of a magnet near the coils. On the basis of their observations in Experiment 9.1, students are introduced to the basic idea of moving a magnet using magnetic fields. 


\subsection{INVESTIGATION WITH ELECTROMAGNETS}

\section{Equipment}

4.3.6. Batteries, wire, nail, pencil, paper clips, magnetic field sensor.

\section{Discussion of the experiments and exercises:}

4.3.1. Students are asked to choose among two predictions made by others

4.3.2. Students are asked to describe an experiment to check one variable that could affect the strength of an electromagnet.

4.3.3. Students are asked to formulate a research question.

4.3.4. Students should be able to understand that when they check one variable, they have to keep all the others constant. They describe the way to do so.
4.3.5. Students are asked to prepare an experiment to check one of the previous variables.

4.3.6. Students should carry out the experiment as they described it previously.

4.3.7. The procedure followed by another group is given and students are asked to discuss it. They must check if all the variables except the one under investigation were kept constant.

4.3.8. Students decide which new variable are going to measure and how.

4.3.9. They carry out the experiment and conclude which variables affect the strength of an electromagnet. 


\section{B: EVALUATION TASKS}

FOR INDIVIDUAL ACTIVITIES OR INDIVIDUAL CHAPTERS OR WHOLE MODULE 


\section{B: EVALUATION TASKS FOR INDIVIDUAL ACTIVITIES OR INDIVIDUAL CHAPTERS OR WHOLE MODULE}

A range of assessment tasks have been employed in order to measure the improvement of the students. The assessment tasks include:

- Tests for each unit $(1,2,3,4)$ of the module.

- A report referring to the literature and development of the model train. The train itself is also assessed according to operation, design features and methodology used for development. This project is a group assessment and the group has to combine knowledge from different chapters to construct the train. The design project (train) has another aspect for students to investigate, this being the magnetic shielding. The students have to refer to the literature using the internet to find materials with the required characteristics. Each group at the end of the module presents its model train and report. The report should focus on the design of the train and the reasoning behind it.

\section{QUESTIONS TEST (UNIT 1 \& 2)}

1. (a) Put a tick $(\checkmark)$ in every correct answer:

$\square$ Magnets interact only with smaller objects.

Magnets interact with all the metals.

$\square$ Magnets interact only with other magnets.

Magnets interact only with objects that contain iron.

Magnets interact with other magnets and objects that contain iron.

(b) Put a tick $(\checkmark)$ beside every object that interacts with magnets.

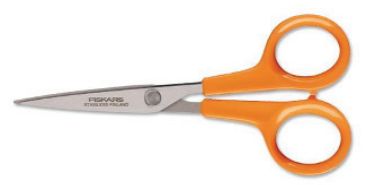

SCISSORS MADE OF STEEL
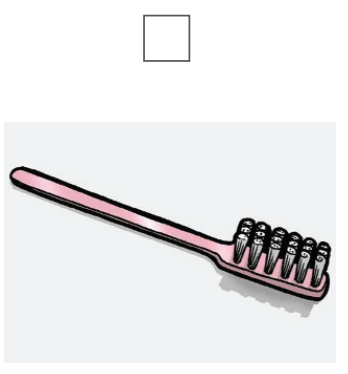

TOOTHBRUSH

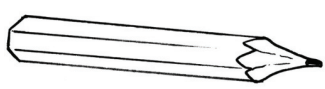

PENCIL
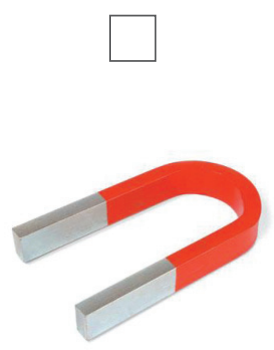

MAGNET

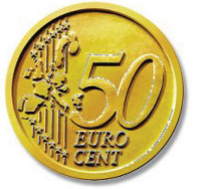

COIN MADE OF AN ALLOY OF COPPER
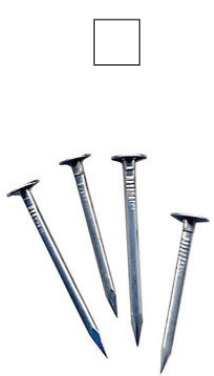

NAILS MADE OF STEEL

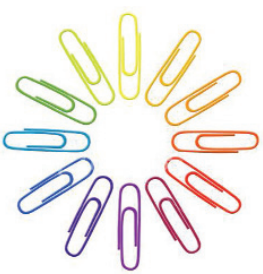

PAPER CLIPS
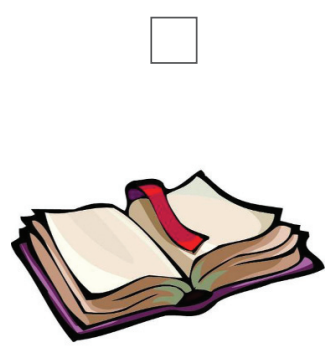

BOOK 


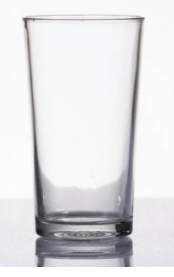

GLASS

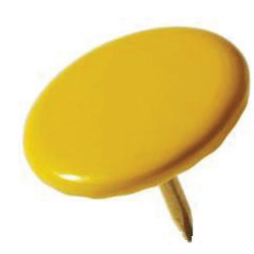

DRAWING PIN

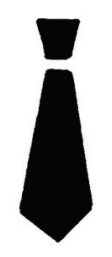

TIE

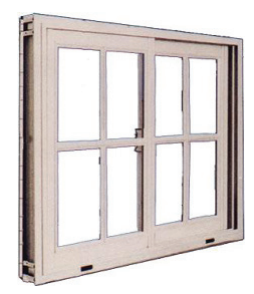

WINDOW MADE OF ALUMINIUM
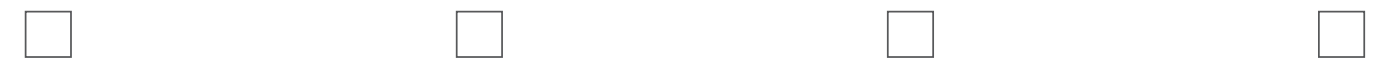

2. Formulate one operational definition for a magnet. Your operational definition should not be possible to be misinterpreted and at the same time must allow other people to recognize whether an object is a magnet or not.

3. (a) A magnet (magnet A) lies on a table. It is coloured half red and half blue. I observe that something happens when I bring a second magnet close to it in position B, as shown below. Describe what is happening between magnets $A$ and $B$. Explain your reasoning.

A

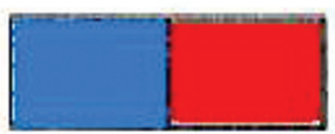

B

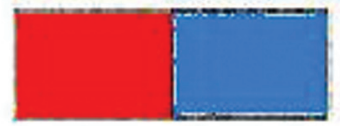

(b) Another magnet $\mathrm{C}$ is lying on a table in some other room. I observe that something happens when I bring a second magnet close to it in position $\mathrm{D}$, as shown below. Describe what is happening between magnets $\mathrm{C}$ and D. Explain your reasoning.

C

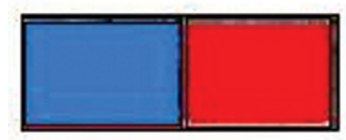

D

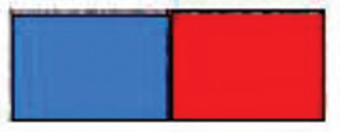


4. After getting involved with several experiments a student comes to the following conclusion:

"A long time ago, someone decided to define 'like' ends of magnets as those that repel one another. In the same manner they could have decided that 'like' ends attract one another and 'unlike' repel one another."

What experiment(s) could a student do in order to decide whether to accept or reject this statement? Describe the experiment and the results you expect to come up. Explain how would these results support or turn down the students' statement.

5. At the following figure ferromagnetic objects are hanged over two different magnets. Show where the magnet poles are.
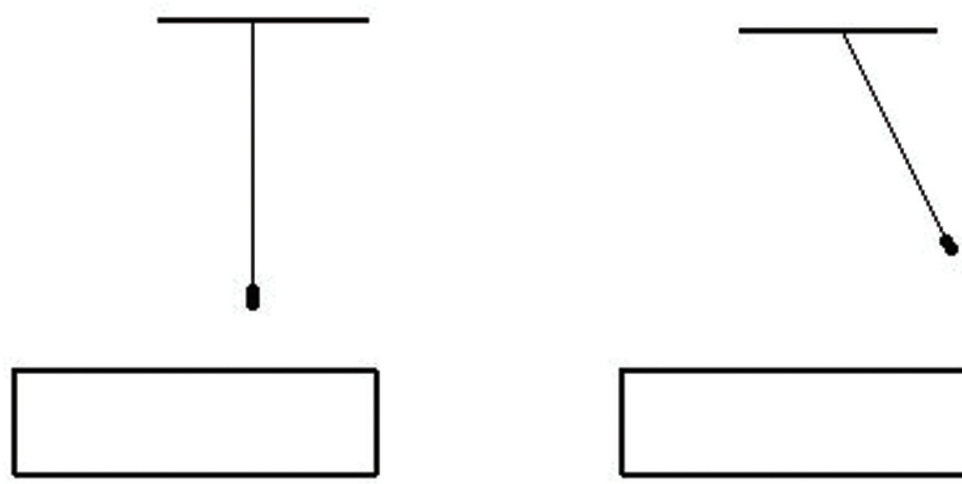

6. Suppose that we have hung some magnetic bars using strings in order to be in horizontal position and to be able to rotate freely. Afterwards, we placed them in several places of a room, far enough from each other so they don't interact. Two students suggest that:

A) "Each magnet will be oriented according to the objects that are around it. If those objects don't interact with the magnets, their orientations will be random."

B) "All magnets will have the same orientation in the room, whatever are the objects close to them."

\section{DISCUSS EACH STUDENT'S PREDICTION REASONING YOUR OPINION.}

7. Imagine that you belong to a crew of a spaceship that is landed on an unknown planet. You realize that the north pole of your compass is pointing at the direction that the sunrise is and the south pole is pointing at the direction of sunset. Where do you think would be the magnetic poles of this planet? Explain your opinion.

8. A student comments that:

"A magnet interacts with the same manner with a nearby ferromagnetic object, no matter if there is also another magnet close to the object"

DISCUSS HIS OPINION. 
9. At figure (a) a magnet is shown along with some compasses around it. At figure (b) two magnets are shown along with two compasses. Show with arrows the orientation of each compass needle and mark its poles.

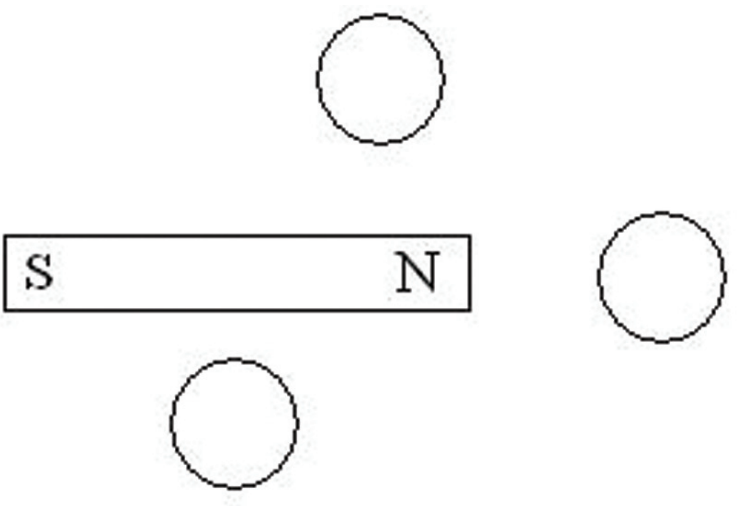

(A)

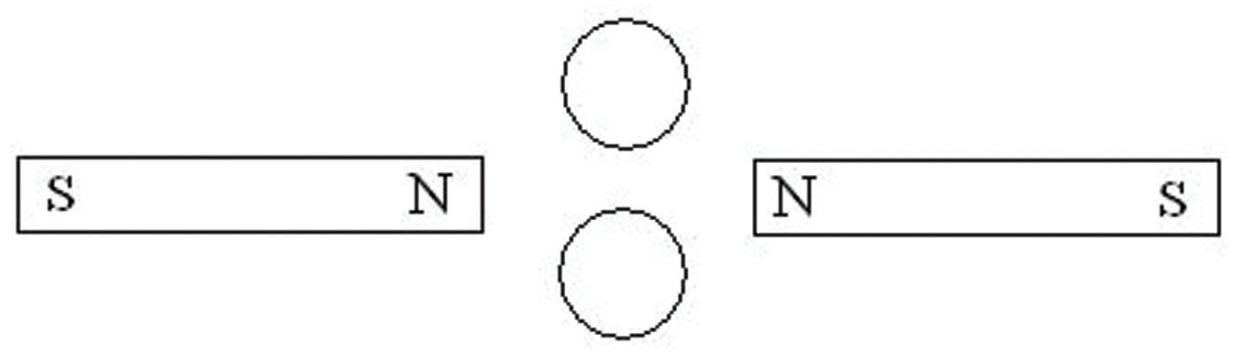

(B)

Explain why you designed the orientations of the compasses like you did. 


\section{RUBRICS UNIT 1 \& 2}

\section{Q2. DEFINITION OF MAGNET}

\begin{tabular}{|l|l|l|}
\hline & CATEGORY OF RESPONSE & TYPICAL STUDENT RESPONSE \\
\hline 1 & $\begin{array}{l}\text { - Distinguishing a magnet from ferromagnetic } \\
\text { materials. } \\
\begin{array}{l}\text { Recognising a magnet in the presence of } \\
\text { another magnet (magnetic interactions: } \\
\text { attraction \& repulsion) }\end{array}\end{array}$ & $\begin{array}{l}\text { A. We have a group of objects and we check them } \\
\text { for interaction, we select the objects that } \\
\text { interact. Between them, the magnet is the } \\
\text { object that attracts all the others that in its } \\
\text { absence the other objects do not interact. } \\
\text { B. If two objects repel then both of these are } \\
\text { magnets. }\end{array}$ \\
\hline 2 & $\begin{array}{l}\text { Distinguishing a magnet from ferromagnetic } \\
\text { materials. }\end{array}$ & $\begin{array}{l}\text { Magnet is the object that attracts/interacts with } \\
\text { other ferromagnetic objects which do not interact } \\
\text { between them. }\end{array}$ \\
\hline 3 & $\begin{array}{l}\text { Interaction with ferromagnetic objects } \\
\text { Attraction/repulsion with other magnets. }\end{array}$ & $\begin{array}{l}\text { Magnets interact with ferromagnetic materials. If } \\
\text { we have two magnets, the opposite poles attract } \\
\text { and the like poles repel. }\end{array}$ \\
\hline 4 & $\begin{array}{l}\text { Attraction/repulsion with other magnets. } \\
\text { Irrelevant answers or answers with internal } \\
\text { inconsistencies }\end{array}$ & $\begin{array}{l}\text { Magnet is a ferromagnetic material with its } \\
\text { magnetic domains aligned. If approached to } \\
\text { another magnet attraction occurs between the } \\
\text { opposite poles and repulsion between the like } \\
\text { poles. }\end{array}$ \\
\hline 5 & $\begin{array}{l}\text { Interaction with metallic objects } \\
\text { Magnets attract all the metallic objects. If the } \\
\text { objects. }\end{array}$ \\
\hline
\end{tabular}




\section{Q7. THE EARTH AS A MAGNET}

\section{CATEGORY OF RESPONSE}

1 - The compass needle is a magnet and its poles can be attracted by the non-alike magnetic poles of the planet.

- The North pole of the compass points towards the South magnetic pole of the planet and vice versa.

2 - The North pole of the compass points towards the South magnetic pole of the planet and vice versa

- No explanation

3 - The compass is oriented according to the geographical poles

- North magnetic pole is located at the geographic South pole and vice versa

4 - The North pole of the compass points towards the North magnetic pole of the planet

5 Irrelevant or no answer

Q9. MAGNETIC FIELDS

\begin{tabular}{|c|c|c|}
\hline & CATEGORY OF RESPONSE & TYPICAL STUDENT RESPONSE \\
\hline 1 & $\begin{array}{l}\text { Magnetic field Interaction: The drawing of the } \\
\text { alignment of the compasses and the explanation } \\
\text { provided illustrate understanding of the form and } \\
\text { effect of the magnetic field. The response implies } \\
\text { an understanding of "interaction at a distance". }\end{array}$ & $\begin{array}{l}\text { "The magnetic field lines begin from the north pole } \\
\text { and end up in the south pole. The magnetic field } \\
\text { lines at the centre of the poles are straight lines, } \\
\text { therefore, the compasses situated near the poles } \\
\text { of the magnet, point towards the magnet's poles } \\
\text { with their opposite pole. The compass in the } \\
\text { middle of the magnet is aligned along the magnetic } \\
\text { field lines following the direction of the magnetic } \\
\text { field." }\end{array}$ \\
\hline 2 & $\begin{array}{l}\text { Interaction between magnets: Magnetic } \\
\text { interactions (attraction \& repulsion between the } \\
\text { poles) determine the orientation of the compasses. }\end{array}$ & $\begin{array}{l}\text { "The compasses near the south pole are } \\
\text { positioned with their opposite (north) pole towards } \\
\text { the magnet's pole. The compass situated in the } \\
\text { middle is separated by an equal distance from the } \\
\text { two poles, thus it is aligned in the opposite } \\
\text { direction of the magnets' poles because its north } \\
\text { pole is attracted by the south pole of the magnet } \\
\text { and the other way around." }\end{array}$ \\
\hline 3 & $\begin{array}{l}\text { Interaction between magnets: The drawing of the } \\
\text { orientation of the compasses shows lack of } \\
\text { understanding of the interaction between the } \\
\text { compass poles and the magnets' poles. }\end{array}$ & $\begin{array}{l}\text { "The needle of compass } 1 \text { is vertically aligned } \\
\text { because the north pole interacts with the south } \\
\text { pole of the magnet. The north pole of compass } 2 \\
\text { is on the left because it interacts with the south } \\
\text { pole of the magnet and again the north pole of } \\
\text { compass } 3 \text { is up and right because it interacts with } \\
\text { the south pole of the magnet." }\end{array}$ \\
\hline 4 & $\begin{array}{l}\text { Irrelevant answers or answers with internal } \\
\text { inconsistencies }\end{array}$ & $\begin{array}{l}\text { "The red needle of the compass always points } \\
\text { towards the North pole. Thus, all the compasses } \\
\text { will point towards the north pole of the magnet with } \\
\text { their north pole." }\end{array}$ \\
\hline
\end{tabular}




\section{QUESTIONS TEST (UNIT 3)}

1. Two magnets like these depicted at the following figure are given.

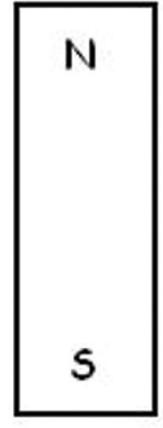

(A)

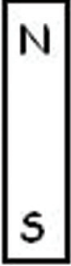

(B)

A) One student suggests that:

"Magnet $A$ is stronger because is bigger".

B) Another student is more wary, so he experiments and finds out that indeed magnet A is stronger. He concludes:

"The strength of a magnet is analogous to its size".

\section{DISCUSS STUDENTS' CONCLUSIONS.}

2. The magnets shown below are given:

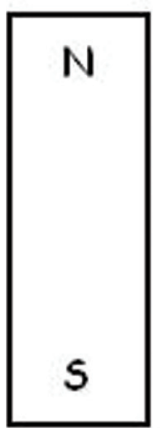

(A)

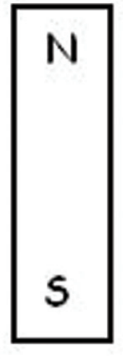

(B)

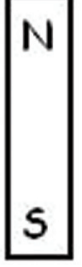

(C)

After measurements it is found that:

i) The south pole of magnet $A$ can hold a chain of 15 clips

ii) The south pole of magnet $B$ can hold a chain of 10 clips

iii) The north pole of magnet $C$ can hold a chain of 17 clips

A) One student suggests that:

"The strength of a magnet is analogous to its size".

B) Another student suggests that:

"North poles of magnets are stronger". 


\section{DISCUSS THEIR COMMENTS.}

3. A magnet, like the one presented in the figure next, is broken to two pieces along the interrupted line, as it is shown.

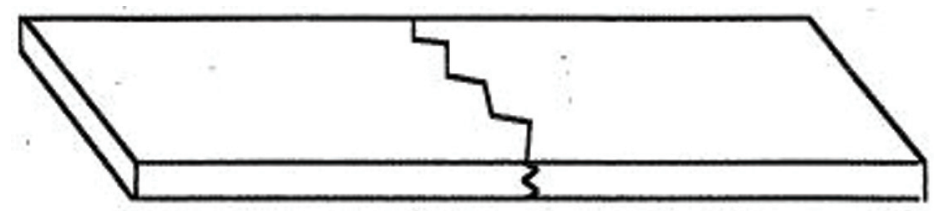

What do you think you would observe if you try to bring back together the two pieces?

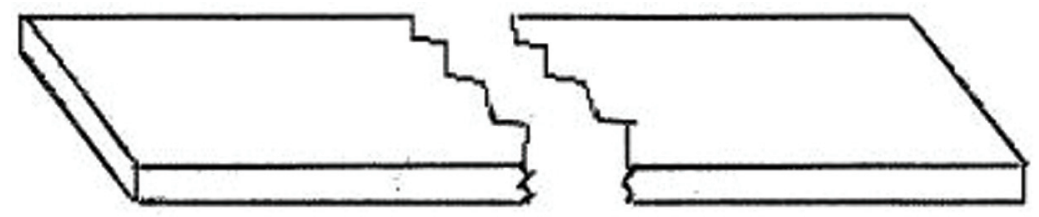

Can you determine the poles of each piece? If yes, show them on the diagram and explain your reasoning. If no, explain why not.

4. (a) One magnetic stack like the one in the figure below, which is consisted of six small magnets, is able to hold at each one of its ends ( $A$ and $B$ ) a chain of 18 clips. The magnetic stack is stable.

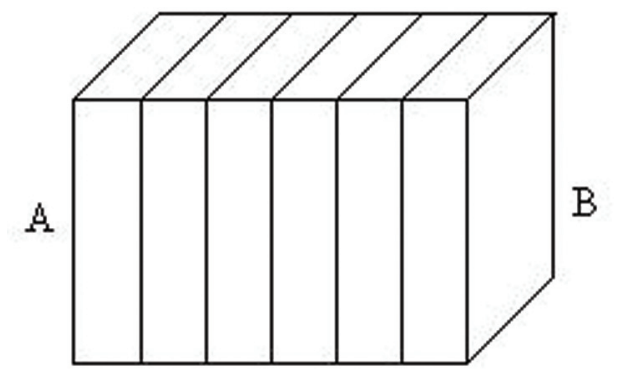

If we split the magnetic stack in two equal pieces, each one of these will be able to hold approximately:

i) 36 clips

ii) 18 clips

iii) 15 clips

iv) 9 clips

Put in circle the correct answer and justify your choice.

(b) Design a magnetic stack using the same 6 magnets, that its edges will be able to hold a chain of clips as small as possible. Magnets can be hold in the stack using rubber bands. Show where the poles of each magnet are and reason why you chose to put them like this. 
5. (a) In the following figure a magnet and a ferromagnetic bar are presented. Draw the magnetic field lines as you think that the pattern of the magnetic field is around the two objects and explain your reasoning.

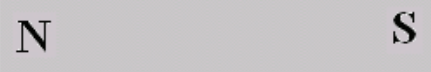

\section{Fenromagnetic Bar}

(b) The same ferromagnetic bar is now cut in two pieces and a compass is placed between them. Show the orientation of the compass needle and explain your reasoning.
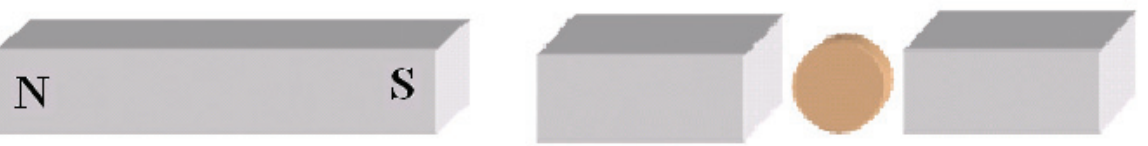

6. In an apparatus like the one presented below, we placed a magnet beside a ferromagnetic planar piece. On this piece there are two holes large enough to fit a compass inside each one. Show the orientation of each compass needle explaining your reasoning.

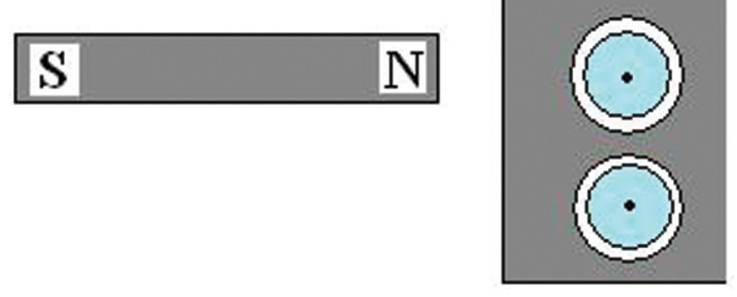

7. If we let a ferromagnetic bar beside a permanent magnet for enough time, the bar becomes also a temporary magnet.

How is the magnetization of the bar explained?

Why is the magnetization lost if we hit the bar with a hammer? 


\section{RUBRICS UNIT 3}

Q5. MAGNETIC MODEL

\begin{tabular}{|c|c|c|}
\hline & DESCRIPTION OF RESPONSE & TYPICAL STUDENT RESPONSE \\
\hline 1 & $\begin{array}{l}\text { When a ferromagnetic material is placed into a } \\
\text { magnetic field ... } \\
\text { - ...its magnetic domains are aligned according } \\
\text { to the direction of the magnetic field. } \\
\text {-...the magnetic field is then formed around the } \\
\text { ferromagnetic material according to its } \\
\text { magnetization. }\end{array}$ & $\begin{array}{l}\text { The ferromagnetic bar consists of many small } \\
\text { magnets (magnetic domains), which are irregularly } \\
\text { placed. When the ferromagnetic bar is placed into } \\
\text { the magnetic field of a permanent magnet, its small } \\
\text { magnets align and the ferromagnetic material } \\
\text { acquires magnetic properties (magnetic poles } \\
\text { appear at its ends). Thus, the ferromagnetic bar } \\
\text { acts from then on as a magnet and when the } \\
\text { compasses are placed near its north pole the } \\
\text { compasses align according to the magnetic field } \\
\text { lines of the ferromagnetic bar. So, the south pole } \\
\text { of the compasses is positioned towards the north } \\
\text { pole of the magnet. }\end{array}$ \\
\hline 2 & $\begin{array}{l}\text { When a ferromagnetic material is placed into a } \\
\text { magnetic field... } \\
\text { - ...it is magnetised and poles appear at its ends. } \\
\text { - ...the magnetic field is then formed around the } \\
\text { ferromagnetic material according to its } \\
\text { magnetization. }\end{array}$ & $\begin{array}{l}\text { The ferromagnetic bar is magnetized when } \\
\text { approached near a magnet and poles appear at its } \\
\text { ends. The poles are determined according to the } \\
\text { magnet's pole that attracts the ferromagnetic bar. } \\
\text { The compasses are oriented according to the } \\
\text { poles of the ferromagnetic bar. }\end{array}$ \\
\hline 3 & $\begin{array}{l}\text { When a ferromagnetic material is placed into a } \\
\text { magnetic field... } \\
\text { - ...it is affected from the generator of the } \\
\text { magnetic field and as a consequence it } \\
\text { acquires magnetic properties. } \\
\text { - the magnetic field is then formed around the } \\
\text { ferromagnetic material accordingly, but no } \\
\text { poles are appeared. }\end{array}$ & $\begin{array}{l}\text { The magnet attracts the ferromagnetic bar. So, the } \\
\text { ferromagnetic bar will be magnetized and will } \\
\text { attract the compass' needle. The compass' needle } \\
\text { will follow the magnetic field lines. }\end{array}$ \\
\hline 4 & $\begin{array}{l}\text { When a ferromagnetic material is placed into a } \\
\text { magnetic field... } \\
\text { - ...it is not affected from the magnetic field and } \\
\text { consequently, } \\
\text { - the magnetic field retains its form around it as } \\
\text { in the case of paramagnetic material. }\end{array}$ & $\begin{array}{l}\text { The south pole of the compass is positioned } \\
\text { towards the north pole of the magnet, because it is } \\
\text { affected by the magnet's magnetic field. Even } \\
\text { though between the compass and the magnet } \\
\text { there is a ferromagnetic bar, the orientation of the } \\
\text { compass will not be affected because the } \\
\text { ferromagnetic bar is not a magnet. }\end{array}$ \\
\hline 5 & $\begin{array}{l}\text { Irrelevant response or response with internal } \\
\text { inconsistencies }\end{array}$ & \\
\hline
\end{tabular}




\section{QUESTIONS TEST (UNIT 4)}

1. Figures 1 to 4 present horizontal wires. In each case a compass is placed exactly over the wire. Determine if there is current flow in each one and, if it does, show the direction that it flows. Explain your reasoning.
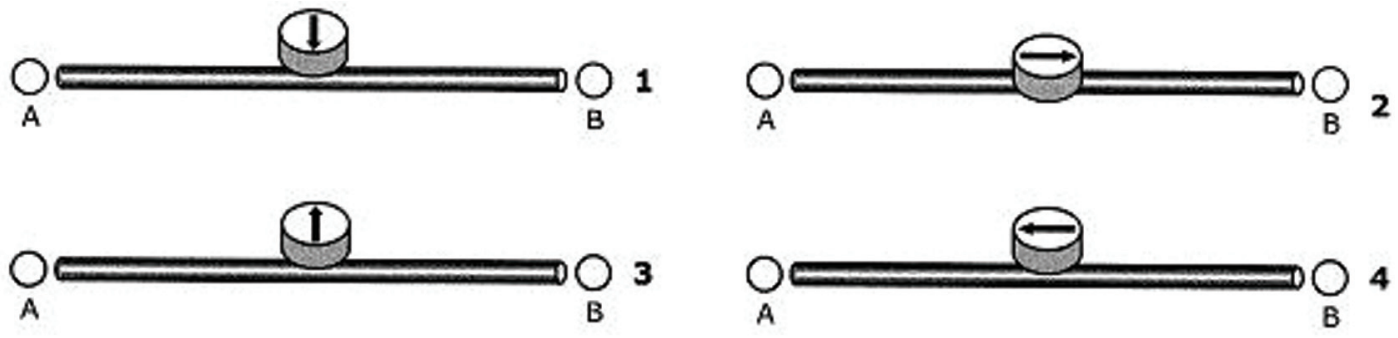

2. Describe and design an apparatus (consistent of a piece of wire and a battery) that has the magnetic properties of a magnetic bar.

3. A student has three metallic bars and one metallic nail wrapped in a piece of wire which is connected to a battery. Each one of the bars may belong in one of the following categories:

i) Permanent magnets

ii) Ferromagnetic objects (non-magnetized)

iii) Objects that cannot be magnetized

The bars and the nail are numbered from 1 to 4 as presented in the following figure. The ends of the bars are also denoted with the letters A or B, while the centre of each bar with the letter m. (Note: At the case of a magnet, the poles will be located at the ends of the bar.)

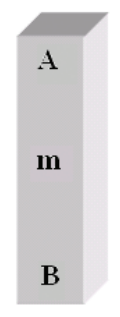

Bar 1

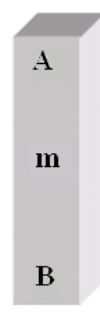

Bar 2

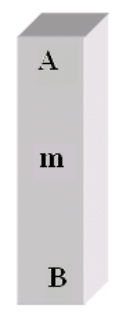

Bar 3

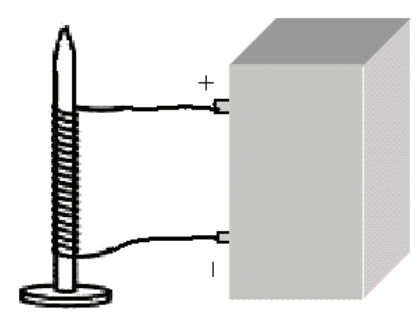

Electomagnet

The student closed the switch and wrote down the following observations:

- $1 \mathrm{~A}$ and $4 \mathrm{~A}$ are attracted to each other

- 2A does not interact with $4 \mathrm{~m}$

- $3 \mathrm{~A}$ and $4 \mathrm{~B}$ are repulsed

(a) Is the bar 1 a permanent magnet? If you are not sure, in which other category(ies) could this bar belong to? (Look at the categories above)

(b) Is the bar 2 a permanent magnet? If you are not sure, in which other category(ies) could this bar belong to? (Look at the categories above)

(c) Is the bar 3 a permanent magnet? If you are not sure, in which other category(ies) could this bar belong to? (Look at the categories above) 
(d) If we approach $1 \mathrm{~A}$ to $1 \mathrm{~B}$, how would these ends react? If it is hard to answer with certainty, state the possible reactions. Explain your reasoning.

4. Describe explicitly an experiment which you could carry out to investigate if the core material of an electromagnet affects the strength of attraction between an electromagnet and a ferromagnetic object.

\section{RUBRICS UNIT 4}

\section{Q1. MAGNETIC FIELD CREATED BY A CURRENT-CARRYING WIRE}

\begin{tabular}{|c|c|}
\hline & CATEGORY OF RESPONSE \\
\hline 1 & $\begin{array}{l}\text { The magnetic field ... } \\
\text { - } \quad \text {...is produced by the flow of electric current through a wire } \\
\text { - } \quad \text {...its direction is perpendicular to the current flow (correct form of magnetic field) } \\
\text { - } \quad \text {...its direction is explained by the idea of the current flow }\end{array}$ \\
\hline 2 & $\begin{array}{l}\text { The magnetic field... } \\
\text { - } \quad \ldots \text { is produced by the flow of electric current through a wire } \\
\text { - } \quad \ldots \text { its direction is perpendicular to the current flow (correct form of magnetic field) } \\
\text {...its direction is not explained by the idea of the current flow }\end{array}$ \\
\hline 3 & $\begin{array}{l}\text { The polarity of the magnetic field (North-South pole) coincides with the polarity of the battery }(+,-) \text { to } \\
\text { which the wire is connected }\end{array}$ \\
\hline 4 & The flow of the magnetic field follows the flow of the electric current \\
\hline 5 & There is no magnetic field around the current flow \\
\hline 6 & None or irrelevant answer \\
\hline
\end{tabular}

\section{Q4. DESIGN OF AN EXPERIMENT ON ELECTROMAGNETS}

\begin{tabular}{|l|l|}
\hline & CATEGORY OF RESPONSE \\
\hline 1 & $\begin{array}{l}\text { - Description of how the variable under investigation (independent variable) is going to be altered } \\
\text { - Description of how the dependent variable is going to be measured } \\
\text { - Reference on the variables that will be kept constant }\end{array}$ \\
\hline 2 & $\begin{array}{l}\text { - Description of how the dependent variable is going to be measured } \\
\text { - Reference on the variables that will be kept constant }\end{array}$ \\
\hline 3 & $\begin{array}{l}\text { - Description of how the variable under investigation (independent variable) is going to be altered } \\
\text { - Description of how the dependent variable is going to be measured }\end{array}$ \\
\hline 5 & Irrelevant or no answer \\
\hline
\end{tabular}



MATERIALS

SCIENCE PROJECT

UNIVERSITY-SCHOOL PARTNERSHIPS

FOR THE DESIGN AND IMPLEMENTATION

OF RESEARCH-BASED ICT-ENHANCED

MODULES ON MATERIAL PROPERTIES

ISBN 978-9963-689-63-7

2009 